[3] Molto et al. Ann Rheum Dis 2016.

[4] Simoes et al. Arthritis Care \& Research 2017.

Disclosure of Interest: None declared

DOI: 10.1136/annrheumdis-2017-eular.2186

\section{FRI0719 BURDEN OF HEPATITIS E VIRUS INFECTION IN PATIENTS WITH RHEUMATIC DISEASES}

P. Jacques $^{1,2}$, E. Padalko ${ }^{3}$, E. Verheugen ${ }^{1,2}$, L. Cattoir ${ }^{3}$, X. Verhelst ${ }^{4}$, E. Nys ${ }^{3}$ S. Van Gucht ${ }^{5}$, V. Hutse ${ }^{5}$, V. Suin ${ }^{5}$, D. Elewaut ${ }^{1,2} .{ }^{1}$ Rheumatology, University Hospital; ${ }^{2}$ VIB, Ghent University; ${ }^{3}$ Clinical Chemistry, Microbiology and Immunology; ${ }^{4}$ Gastroenterology, University Hospital, Ghent; ${ }^{5}$ National Reference Centre for Viral Hepatitis, Scientific Institute of Public Health, Brussels, Belgium

Background: Hepatitis E virus (HEV) is considered an emerging pathogen in developed countries, potentially causing chronic hepatitis.

Objectives: This cross-sectional analysis was undertaken to determine the seroprevalence of HEV in patients with autoimmune or inflammatory arthritis. This subgroup of patients is often treated with immune suppressive drugs, and is generally considered more susceptible to infections.

Methods: Serum samples were obtained from 449 consecutive patients consulting at the department of Rheumatology between October and November 2015. Patient characteristics with respect to diagnosis and treatment were collected. HEV IgM and IgG were measured by ELISA (Wantai Hepatitis E Virus IgG and IgM ELISA, Sanbio BV). Positive or borderline samples were further analyzed for HEV RNA (RealStar ${ }^{\circledR}$ HEV RT-PCR Kit, Altona Diagnostics NRC WIV).

Results: A total of 449 patients were included, 211 men and 238 women. HEV IgG was positive in 82 samples (18.26\%), 6 were borderline, and 5 were nondeterminable (not enough serum). IgM was positive in only 2 samples $(0.45 \%)$. These 2 patients had normal liver function tests. Additional PCR was performed on all positive and borderline samples, which turned out negative in all samples. Of the $88 \mathrm{lgG}$ positive and borderline samples, 86 patients had a known diagnosis of chronic inflammatory arthritis, of which 50 patients had previously been diagnosed with rheumatoid arthritis, 18 with spondyloarthritis, 8 with psoriatic arthritis. Fifty patients were treated with biologics (37 TNF inhibitors), 43 patients were treated with methotrexate (mean dose $12.5 \mathrm{mg}$ weekly), and 20 were treated with corticosteroids (mean daily dose $5.5 \mathrm{mg}$ prednisolone equivalent).

Conclusions: In a consecutive cohort of patients with known diagnosis of autoimmune or inflammatory arthritis, seroprevalence of HEV IgG was $18,2 \%$. No active HEV infection could be detected. We found this to be comparable to a historical cohort of healthy patients from the departments of Orthopedics and obstetrics $^{1}$, where prevalence of HEV IgG was $14 \%$.

References:

[1] Van Hoecke F et al. Acta Gastroenterol Belg. 2012 Sep;75(3):322-4. Disclosure of Interest: None declared

DOI: 10.1136/annrheumdis-2017-eular.5115

\section{FRI0720 CHARACTERISTICS OF PATIENTS WITH GOUT TREATED TO SUA TARGET THAT CONTINUE TO EXPERIENCE FLARES: DATA FROM FRANCE, GERMANY, ITALY, SPAIN, UK AND US}

R. Morlock ${ }^{1}$, D.C. Taylor ${ }^{2}$, S. Baumgartner ${ }^{3} .{ }^{1}$ YourCareChoice, Ann Arbor; ${ }^{2}$ Health Economics and Outcomes Research, Ironwood Pharmaceuticals, Cambridge; ${ }^{3} d r B$ Consulting, Spokane, United States

Background: Gout is a common form of inflammatory arthritis. Treatment guidelines recommend a target serum urate $(\mathrm{s} \cup A) \leq 6 \mathrm{mg} / \mathrm{dL}$. ACR and EULAR treatment guidelines indicate SUA targets may need to be surpassed to achieve treatment benefits in a subset of patient that continue to flare and/or have tophi. Methods: Data were assessed from a survey of physicians about gout disease management. Patient results were confirmed through in-depth chart audits assessing diagnosis, comorbid conditions, disease severity and laboratory assessments. Disease severity was measured using a physician global assessment, flare counts, joint damage and presence of tophi. Type and dose of XOI, length of current treatment, compliance, physician type and patient socio-demographic factors were identified. Descriptive and multivariate statistics were used to describe patients having $\geq 2$ flares per year (excluding treatment-related flares) in patients achieving target sUA $\leq 6 \mathrm{mg} / \mathrm{dL}$.

Results: Overall, 251 rheumatologists and 250 primary care physicians were interviewed and provided data from 2505 patients with gout; $82 \%$ were male and the average age was 58 years $(\mathrm{SD}=12) .1823(73 \%)$ patients were treated with an XOI, of these $813(44 \%)$ had a least one assessment of sUA $\leq 6 \mathrm{mg} / \mathrm{dL}$ over a 12-month period. Of the 813 patients reaching sUA target, $307(37.8 \%)$ reported $\geq 2$ flares in the last year. On average, patients at sUA goal with $\geq 2$ flares had been treated over 38.8 months on their current $\mathrm{XOI}$ and patients with $\leq 1$ flare had been treated for 40.7 months. Patients at sUA $\leq 6 \mathrm{mg} / \mathrm{dL}$ treated with an $\mathrm{XOI}$ and reporting $\geq 2$ flares a year were more likely to have tophi $(32.9 \%$ vs. $19.2 \% ; p<0.01$ ), alcoholism (22.8 vs. $10.7 ; p<0.01$ ), CVD (24.8 vs. $17.6 \%$; $p=0.014$ ), depression (14.3 vs. 9.3; $p=0.027$ ), and diabetes mellitus (23.8 vs. $16.8 ; p=0.015)$ compared to patients with $\leq 1$ flare a year. A backward stepwise multivariate model predicting patients classified as controlled ( $\mathrm{s} U \mathrm{~A} \leq 6 \mathrm{mg} / \mathrm{dL}$ ) and continuing to flare ( $\geq 2$ flares in the last year) found the physician-reported and chart-documented comorbidities of chronic kidney disease (OR 1.9; $p<0.01$ ), alcoholism (OR 2.4; $p<0.01$ ), diabetes mellitus (OR 1.5; $p<0.05$ ), and have tophi $(1.7 ; p<0.01)$ to be associated with having higher flare rates despite achieving $\mathrm{sUA} \leq 6 \mathrm{mg} / \mathrm{dL}$. There was no difference by the type of XOI or physician.

Conclusions: Of the patients achieving target sUA level of $\leq 6 \mathrm{mg} / \mathrm{dL}, 62 \%$ have $\leq 1$ flare; however, over a third reported $\geq 2$ in a 12 -month period. Patients with multiple flares were more likely to have higher urate burden in the form of tophi, chronic kidney disease, alcoholism, and diabetes mellitus comorbid conditions. Frequent flares and greater tophaceous burden may require treating more aggressively to an sUA level of $5 \mathrm{mg} / \mathrm{dL}$ or lower as recommended by treatment guidelines.

Acknowledgements: This study was funded by Ironwood Pharmaceuticals.

Disclosure of Interest: R. Morlock Consultant for: Ironwood Pharmaceuticals, D. Taylor Employee of: Ironwood Pharmaceuticals, S. Baumgartner Consultant for: Ironwood Pharmaceuticals

DOI: 10.1136/annrheumdis-2017-eular.6142

\section{FRI0721 SLEEP DISORDERS IN PATIENTS AT THE FIRST ACCESS TO A RHEUMATHOLOGY OUTPATIENT CLINIC}

R. Tirri, D. Capocotta, R. Ferrara. Department of internal and experimental Medicine, Unit of Rheumatology of Univerity of study of Campania "Luigi Vanvitelli", Naples, Italy

Background: Sleep disturbances are frequently found in patients affected by rheumatic conditions (1). Chronic pain, the most common manifestation of these conditions is associated to poor sleep (2)

Objectives: Our primary objective was to evaluate prevalence of excess daytime sleepiness and impaired sleep quality in a patient population at the first access to a Rheumatology outpatient clinic. Secondary objective was evaluation of pain and others factors well known to be associated to sleep disorders.

Methods: 961 out of 1454 (mean age was 52.6 years; $14.3 \%$ were male) consecutive patients admitted for the first time to an Italian Rheumatology Outpatient Clinic, between December 2014 and November 2016, accepted to answer a self-administered questionnaire study. We considered the following parameters: pain intensity on visual analogic scale ranging from 0 to 100 according to commonly used classification (3), patient's assessment of General Health (GH), Epworth Sleepiness Scale (ESS), Pittsburgh Sleep Quality Index (PSQI), Health Assessment Questionnaire (HAQ), and Body Mass Index (BMI). Smoke habits were also considered.

Results: 70 patients showed both sleep disorders $(7.3 \%), 624$ patients had only impaired sleep quality $(64.9 \%)$, 25 showed isolated excessive daytime sleepiness (2.6\%). 242 patients did not have any sleep disorders $(25.2 \%)$. We found that the presence of both $E S S \geq 10$ and $P S Q I \geq 5$ was correlated to moderate-severe pain VAS pain $>40, \mathrm{BMI}>35, \mathrm{HAQ}>1$ and $\mathrm{GH}>50$ with a statistical significance (respectively $p=0.004 ; p=0.032 ; p=0.0004 ; p=0.0001$ ). A correlation with $\mathrm{GH} \geq 50$ in the patient group with only PSQI $\geq 5$ was detected $(p=0.03)$. Smoke habits did not correlate with sleep disturbance measures investigated. No other correlations were found in the other groups.

Conclusions: Thus excess daytime sleepiness and impaired sleep quality may be a target of therapeutic intervention in the treatment of rheumatic conditions. Further studies are needed to generalize results and suggestions.

References:

[1] Generaal E, Vogelzangs N, Penninx WJH, Dekker J. Insomnia, sleep duration, depressive symptoms, and the onset of chronic multisite musculoskeletal pain Sleep 2017; 40.

[2] Vivien C Abad, Priscilla S.A. Sarinas, Christian Guilleminault. Sleep and rheumatologic disorders. Sleep Medicine Reviews 2008; 12: 211-228.

[3] Jensen MP, Chen C, Brugger AM. Interpretation of visual analog scale ratings and change scores: a reanalysis of two clinical trials of post-operative pain. $J$ Pain 2003;4:407-14

Disclosure of Interest: None declared

DOI: 10.1136/annrheumdis-2017-eular.6313

\section{FRI0722 CROSS-SECTIONAL ASSOCIATIONS BETWEEN DEMOGRAPHIC, JOB RELATED, HEALTH RELATED AND PSYCHOSOCIAL FACTORS AND THREE DIFFERENT MEASURES OF PRESENTEEISM: RESULTS FROM EULAR-PRO AT-WORK PRODUCTIVITY STUDY}

S. Leggett ${ }^{1}$, D. Lacaille ${ }^{2}$, A. Boonen ${ }^{3}$, C. Mihai ${ }^{4}$, S. Talli ${ }^{5}$, S. Hagel ${ }^{6}$, S. Dadoun ${ }^{7}$, S. Ramiro ${ }^{8}$, A. Bosworth ${ }^{9}$, G. Sakellariou ${ }^{10}$, S. Verstappen ${ }^{1,11}$ on behalf of EULAR-PRO at-work productivity co-investigators. ${ }^{1}$ Arthritis Research UK Centre for Epidemiology, University of Manchester, Manchester, United Kingdom; ${ }^{2}$ University of British Columbia, Vancouver, Canada; ${ }^{3}$ Maastricht UMC, Maastricht, Netherlands; ${ }^{4}$ Dr. Ion Cantacuzino Hospital, Bucharest, Romania; ${ }^{5}$ East Tallinn Central Hospital, Tallinn, Estonia; ${ }^{6}$ Lund University and Skane University hospital, Lund, Sweden; ${ }^{7}$ APHP Pitie-Salpetriere Hospital, Paris, France; ${ }^{8}$ Leiden UMC, Leiden, Netherlands; ${ }^{9}$ NRAS, Maidenhead, United Kingdom; ${ }^{10}$ IRCCS Policlinico San Matteo Foundation, Pavia, Italy; ${ }^{11}$ NIHR Manchester Musculoskeletal BRU, Central Manchester NHS Trusts, Manchester, United Kingdom

Background: Several measures of at-work productivity loss (i.e. presenteeism) 
exist, varying in concept, recall period, and attribution ${ }^{1}$. As a consequence, the contribution of contextual factors may vary which has important implications when considering these factors in studies evaluating the impact of inflammatory arthritis (IA) and osteoarthritis (OA) on presenteeism.

Objectives: To determine demographic, job related and health related factors associated with three different global measures of presenteeism in patients with IA or OA.

Methods: This large cross-sectional international EULAR-PRO study ( $n=8$ countries) includes patients with RA, PsA, AS or OA in paid employment. Data collection included: demographics, job characteristics, health related and psychosocial factors. Patients also completed three global measures of presenteeism, varying in content, attribution and recall period. The Work Productivity Scale-Arthritis (WPS-A) measuring the affect of arthritis on productivity during the last 7 days, the Work Productivity and Activity Impairment Questionnaire (WPAI) measuring interference of arthritis on work productivity in the last month, and the Work Ability Index (WAI) a generic scale measuring current ability to work. For interpretation purposes the scale of the WAI was reversed in this study. Due to skewed data, univariable median regression analyses were performed to assess the association between independent variables with each individual presenteeism instrument. Results: 503 patients with IA/OA were recruited in this study with a mean age of 47 (SD10) yrs and disease duration of 12.6 (SD10) yrs. Except for male patients reporting a lower WPS-A score, no other demographics were significantly associated with presenteeism (table). Being neutral/unsatisfied about the job, not being able to organize one's own work, reporting higher VAS well-being and disability scores, and experiencing reduced quality of life were all significantly associated with higher presenteeism, a result observed for all three instruments. Furthermore, those with higher anxiety and depression scores also reported having more problems at work due to ill health. Discrepancies between instruments were especially observed between the WPAI (affect of ill health on productivity)/WPS-A (interference ills health on productivity) and WAI (generic scale on ability to work) in relation to job demands, receiving help from colleagues and the option to postpone work.

\begin{tabular}{|c|c|c|c|}
\hline & $\begin{array}{c}\text { WPAI } \\
\text { B(95\%Cl) }\end{array}$ & $\begin{array}{l}\text { WPS-RA } \\
\text { B }(95 \% \mathrm{CI})\end{array}$ & $\begin{array}{c}\text { WAI } \\
\text { B(95\%Cl) }\end{array}$ \\
\hline \multicolumn{4}{|l|}{ Demographics: } \\
\hline $\begin{array}{l}\text { Age, years } \\
\text { Gender, female }\end{array}$ & $\begin{array}{l}0(-0.03,0.03) \\
0(-0.51,0.51)\end{array}$ & $\begin{array}{c}0(-0.03,0.03) \\
-1(-1.60,0.40)\end{array}$ & $\begin{array}{l}0(-0.02,0.02) \\
0(0.51,0.51)\end{array}$ \\
\hline \multicolumn{4}{|l|}{ Job characteristics: } \\
\hline $\begin{array}{l}\text { Job demands: } \\
\text { not/bit demanding } \\
\text { demanding } \\
\text { very demanding }\end{array}$ & $\begin{array}{c}1 \\
0(-0.72,0.72) \\
2(0.25,1.75)\end{array}$ & $\begin{array}{c}1 \\
1(0.12,1.88) \\
1(0.09,1.91)\end{array}$ & $\begin{array}{c}1 \\
0(-0.45,0.45) \\
0(-0.47,0.47)\end{array}$ \\
\hline $\begin{array}{l}\text { Job satisfaction: } \\
\text { very satisfied } \\
\text { neutral } \\
\text { unsatisfied }\end{array}$ & $\begin{array}{c}1 \\
1(0.03,1.97) \\
1(-0.08,2.08)\end{array}$ & $\begin{array}{c}1 \\
2(1.35,2.46) \\
2(1.28,2.72)\end{array}$ & $\begin{array}{c}1 \\
1(0.11,1.89) \\
1(0.00,2.00)\end{array}$ \\
\hline $\begin{array}{l}\text { Help colleagues: } \\
\text { often/always } \\
\text { sometimes } \\
\text { never }\end{array}$ & $\begin{array}{c}1 \\
0(0.49,0.49) \\
-1(-1.63,-0.37)\end{array}$ & $\begin{array}{c}1 \\
0(-0.75,0.75) \\
-1(-1.95,-0.05)\end{array}$ & $\begin{array}{c}1 \\
0(-0.49,0.49) \\
0(-0.63,0.63)\end{array}$ \\
\hline $\begin{array}{l}\text { Able to postpone tasks } \\
\text { often/always } \\
\text { sometimes } \\
\text { Never }\end{array}$ & $\begin{array}{c}1 \\
0(0.60,0.60) \\
1(0.30,1.70)\end{array}$ & $\begin{array}{c}1 \\
0(-0.60,0.60) \\
1(0.30,1.70)\end{array}$ & $\begin{array}{c}1 \\
0(-0.49,0.49) \\
0(-0.57,0.57)\end{array}$ \\
\hline $\begin{array}{l}\text { Able to organise work } \\
\text { often/always } \\
\text { sometimes } \\
\text { never }\end{array}$ & $\begin{array}{c}1 \\
1(015,1.85) \\
2(0.55,3.45)\end{array}$ & $\begin{array}{c}1 \\
0(-0.55,0.55) \\
1(0.06,1.94)\end{array}$ & $\begin{array}{c}1 \\
1(0.32,1.68) \\
1(-0.16,2.16)\end{array}$ \\
\hline \multicolumn{4}{|l|}{ PRO's: } \\
\hline VAS well-being & $0.07(0.06,0.08)$ & $0.06(0.05,0.07)$ & $0.04(0.03,0.05)$ \\
\hline HAQ-score & $4(3.52,4.47)$ & $4(3.50,4.50)$ & $2.67(2.15,3.19)$ \\
\hline EQ-5D & $-6.50(-7.28,-5.71)$ & $-5.82(-6.67,-4.96)$ & $-3.22(-3.85,-2.58)$ \\
\hline HAD-Anxiety & $0.22(0.18,0.27)$ & $0.20(0.16,0.24)$ & $0.11(0.07,0.15)$ \\
\hline HAD-Depression & $0.31(0.24,0.39)$ & $0.33(0.27,0.39)$ & $0.27(0.22,0.33)$ \\
\hline
\end{tabular}

WPAI $(0=$ condition no effect on work $-10=$ condition completely prevented work): WPS-IA $/ O A(0=$ no interfer
$10=$ complete interference: WAI,$\langle 0=$ work ability at its best $-10=$ completely unable to work $)$ : PRO's=patient

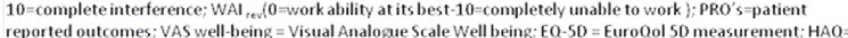
reported outcomes: $V A S$ well-being $=$ Visual $A$ analogue $S$ cale Well being: $E Q-S D=$ EuroOol $S D$ measurement: $\mathrm{HAQ}=$
health assessment questionnaire; $H A D=$ Hospital Anxiety and Depression scale. Bold values $=$ Statistically significant (p<0.05).

Conclusions: This is the first study investigating the association of many contextual factors with three commonly used global measures of presenteeism. Overall, job satisfaction and the ability to organize one's own work are the most important job characterises associated with presenteeism and should be considered when measuring presenteeism.

References:

[1] Ref. Leggett et al. Content validity of global measures for at-work productivity. Rheumatology, 2016;55:1364.

Acknowledgements: Funding: EULAR, AbbVie, BMS.

Disclosure of Interest: None declared

DOI: 10.1136/annrheumdis-2017-eular.5161

\section{FRI0723 TEMPORAL PATTERNS OF SEDENTARY BEHAVIOUR AND PHYSICAL ACTIVITY IN PATIENTS WITH RHEUMATOID ARTHRITIS}

S.A.M. Fenton ${ }^{1,2}$, J.L. Duda ${ }^{1}$, J.J. Veldhuijzen van Zanten $^{1,2}$, G.S. Metsios ${ }^{3}$, P.C. Rouse ${ }^{4}$, C.-A. Yu ${ }^{5}$, G.D. Kitas ${ }^{2} .{ }^{1}$ School of Sport Exercise and Rehabilitation Sciences, University of Birmingham, Birmingham; ${ }^{2}$ Rheumatology, Russells Hall Hospital, Dudley; ${ }^{3}$ Faculty of Education, Health and Wellbeing, Institute of Sport, Wolverhampton; ${ }^{4}$ Department for Health, University of Bath, Bath; ${ }^{5}$ School of Biomedical Sciences, University of Leeds, Leeds, United Kingdom

Background: Rheumatoid Arthritis (RA) is associated with increased risk of cardiovascular disease (CVD). Recent evidence suggests sedentary behaviour (waking behaviour $\leq 1.5$ metabolic equivalents whilst sitting/lying) may contribute towards the progression of RA outcomes, including heightened CVD risk (1). Sedentary behaviour occupies the majority of waking hours among people with RA (1). However, the proportion of time spent sedentary is likely to fluctuate over the course of the day, with periods of high sedentarity representing more optimal opportunity for intervention, and thus potentially higher intervention efficacy.

Objectives: The aims of this study were; 1) to explore temporal patterns of sedentary behaviour (and physical activity) among RA patients, and 2) to examine associations between temporal sedentary patterns and predicted 10-year risk of CVD.

Methods: Patients with RA ( $N=97)$ wore a GT3X accelerometer for 7 days to assess habitual sedentary time $(<100$ counts/min) and physical activity (PA; light $=100-2019$, moderate-to-vigorous $=\geq 2020$ counts $/ \mathrm{min})$. Accelerometer data were analysed separately for each hour (valid hour criteria; 60-minutes of data on $\geq 3$ days, including a weekend day). To evaluate 10-year risk of CVD (Q-risk2), patients reported their medical history, provided a fasted blood sample and underwent assessments of blood pressure and body-mass index.

Results: Temporal patterns of sedentary time and PA are reported in Figure 1. Sedentary time declined throughout the morning (08:00-12:00). During the afternoon, sedentary time increased by 4.5 minutes (12:00-18:00; $M$ $=34.36 \pm 8.86$ to $\mathrm{M}=39.06 \pm 7.91)$. A more marked increase in sedentary time was observed during leisure time (18:00-22:00; $M=39.61 \pm 7.59$ to $M=47.90 \pm 6.30$ ). Repeated measures analysis of variance (ANOVA) revealed sedentary time was significantly higher during leisure time ( $M=46.20 \pm 5.46)$ compared to the morning $(M=36.88 \pm 5.61)$, and afternoon $(M=38.50 \pm 6.07)[N=28, \quad F(2,26)=43.48$, $p=<0.01]$. Significant differences remained after accounting for employment status (i.e., employed vs. unemployed/student, $F(2,23)=1.40, p=0.27$ ). Patients who accumulated $M=>45.31$ sedentary minutes during their leisure time (18:00-23:00, median split), had significantly higher 10-year risk of CVD ( $M=22.23 \pm 13.83$ ) compared to those accruing $M=<45.31$ sedentary minutes $(\mathrm{M}=8.09 \pm 7.62)[\mathrm{t}(41)=3.92, p=<0.01]$. Finally, hourly patterns for light $\mathrm{PA}$ were the reverse of those observed for sedentary time. Hourly MVPA engagement was consistently $<3$ minutes (peak MVPA at 09:00-10:00, $M=2.47 \pm 4.16$ ).

Figure 1. Temporal patterns of sedentary time, light and moderate-to-vigorous physical activity

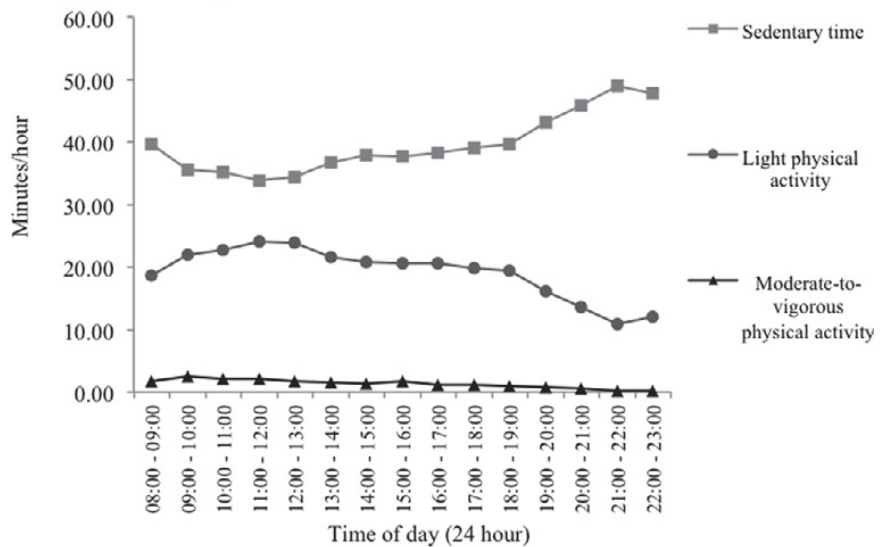

Note: Valid data available at each time point ranged from $\mathrm{N}=49(08: 00)$ to $\mathrm{N}=71$ (13:00). A total of $\mathrm{N}=41$ participants provided complete data across all hours during the morning $(08: 00-12: 00)$ and leisure time $(18: 00-23: 00)$. $\mathrm{N}=64$ participants complete data during the afternoon $(12: 00-18: 00)$.

Conclusions: Interventions targeting leisure time sedentary behaviour (18:0023:00), relative to more occupational sedentary behaviour (08:00-18:00), may offer the greatest potential for sedentary time reduction and associated improvements of CVD risk profile. Due to inverse patterns of engagement, replacing leisure time sedentary behaviour with light PA may offer an effective intervention approach.

References:

[1] Fenton SAM \& Kitas GD. Rheumatoid Arthritis: Sedentary behaviour in RA a new research agenda. Nat Rev Rheumatol 2016;12(12):698-700.

Disclosure of Interest: None declared

DOI: 10.1136/annrheumdis-2017-eular.590 